\title{
Transformation and Development of Taobao Village in China Based on "Zhijiang Mode"
}

\author{
Saidi Yang ${ }^{1}$, Puqing Wang ${ }^{1, *}$ and Deyi Zhou ${ }^{2}$ \\ ${ }^{I}$ School of Economics and Management, Wuhan Polytechnic University, Wuhan, Hubei 430023, China \\ ${ }^{2}$ School of Economics and Management, Huazhong Agricultural University, Wuhan, Hubei 430070, China \\ *Corresponding author.Email: zsb@whpu.edu.cn.
}

\begin{abstract}
This paper focused on the "Zhijiang mode", analyzed its development advantages and difficulties, and put forward corresponding suggestions for the transformation and development of China's Taobao village, as well as provided new ideas for the areas in the central and western regions that are building or want to build Taobao village. This paper adopted a case study method to qualitatively analyze the formation and operation mechanism of the "Zhijiang mode", and followed a "practice-theoretical" path study. It is found that the "leading e-commerce enterprise + cooperative + farmers + base" mode in Zhijiang City is replicable, and can become a model for the development of the central and western regions. The transformation of China's Taobao villages needs to gradually replace government-led development with service provider-led development, focus on balancing, improve the competitiveness of e-commerce, and learn to use data to serve the industry.

Keywords: rural e-commerce, Taobao Villages, digital village, Zhijiang Mode
\end{abstract}

\section{INTRODUCTION}

From 2009 to the present, China's Taobao villages have demonstrated important economic and social values in terms of increasing farmers' income, promoting industrial prosperity, and stimulating return home entrepreneurship. Now Taobao village has become the pioneer of rural revitalization strategy[1]. At present, China's Taobao village is in the 2.0 mode of industrial upgrading and rapid expansion. However,with the continuous development of the business model of China's Taobao Village, the construction of Taobao Village also faces many new issues that cannot be ignored, such as the "involution" of the development of e-commerce industry under excessive competition (Luo et al., 2019)[2], the product innovation within clusters is in a stagnant phase[3], logistics and warehousing system is still the "bottleneck" of rural ecommerce development. In addition, looking at the spatial distribution of Taobao villages in China, the number of Taobao villages has shown a significant increase, but the spatial evolution in the way of spatial diffusion is fissile rather than linear (Liu et al.,2016)[4]. There is a gap between the central and western Taobao villages and the eastern Taobao villages, which is difficult to bridge in a short period. These problems indicate that China's Taobao villages are in urgent need of transformation and upgrading to a 3.0 mode of comprehensive optimization and modernization of collaborative rural governance.

Current academic research on Taobao villages is more focused on three categories: the formation mechanism of Taobao village ${ }^{[5]}$, the development mode of Taobao village[6] and the spatial agglomeration characteristics of Taobao village[7]. The research on the transformation and development of Taobao villages is relatively weak, and there is little research on the development mode of Taobao village in the central and western regions. In other words, how does the development of Taobao villages in the central and western regions differ from that in developed regions, how does the central and western regions develop Taobao villages without inherent advantages, and how does the development of Taobao villages transform in response to existing problems in China have yet to be clarified. Therefore, this paper focuses on the analysis of Zhijiang mode, discusses the formation mechanism and operation mechanism of Zhijiang mode, so as to propose corresponding ideas for the transformation of China's Taobao village development, as well as to provide new ideas for regions that are building or want to build Taobao villages. This paper adopts a case study method to qualitatively analyze the formation and operation mechanism of Zhijiang mode, and also follows the "practice-theoretical" path of research, i.e., to go to the field without subjective bias to carry out field research, to summarize the theoretical framework and point out its uniqueness (Zeng, 2016)[8].

\section{DEVELOPMENT OF TAOBAO VILLAGE IN CHINA}

From 2009 to now, the development of Taobao villages in China has experienced three stages: germination, diffusion and outbreak (ALI Research Institute, 2019)[9]. In the early stage, the combination of marginal people and 
marginal cities promoted the sprouting of Taobao village. However, in the stage of diffusion, industries gradually gathered and government empowerment began. Nowadays the e-commerce market is gradually sinking, the government attaches great importance to the construction of digital villages, and policy dividends are driving the development of Taobao Village into the outbreak period. The number of Taobao villages can be said to have grown in a spurt, from 3 in 2009 to 4,310 today. Taobao village clustering is characterized by a fissile proliferation, with the number of Taobao villages in the six coastal provinces accounting for $95.4 \%$ of the country's total. Zhejiang Province is particularly prominent, the number of Taobao villages will reach 1573 in 2019. Based on the analysis of data from the Ali Research Institute and the Spatial Planning Research Center of Nanjing University, it can be seen that in 2014 Taobao villages were mainly concentrated in the eastern coastal region. While by 2019 they have shown a gradient development trend in the east and the west, forming a more obvious north, middle and south three regional clusters, with the eastern coastal region's radiation development role driven significantly. However, combined with the changes in the number of Taobao villages in specific provinces, the distribution of Taobao villages in 2014-2019 grew by 15 provinces, but the total number of new provinces accounted for only $2.0 \%$ of the total number of new Taobao villages. What's more, it is the fission growth of coastal areas such as Guangdong Province and Zhejiang Province, that is, the spatial change of Taobao villages did not show a high degree of expansion, but rather the development of the adjacent range based on the original concentration of areas. Taobao village is classified into seven categories. The main types of industries in Taobao Village have remained largely unchanged for ten years, mainly agricultural trade, industrial trade and pure trade types.

Combined with the development of Taobao village in China for several years, we can find that there are some problems in the development of Taobao village. On the one hand, the construction of Taobao village relies too much on the government and the successful Taobao village, resulting in fission agglomeration; on the other hand, Taobao village in Zhejiang Province, Jiangsu Province and Shandong Province has summed up its unique development mode, such as "Shaji mode" and "Shuyang model"[10]. In addition, from the perspective of industrial types, Taobao village is still marginal personnel in the marginal areas, and it is not the mainstream construction that Taobao village has developed by using edge products. Therefore, the next step in the transformation of Taobao Villages to a fully optimized village is how to expand the Taobao Village space in China, how to allow more regions to use the Taobao Village to drive economic development and build a digital village, and how to move from the periphery to the mainstream, from commercial innovation to social innovation.

\section{CASE ANALYSIS}

Up to now, Zhijiang City has built 3 Taobao towns and 10 Taobao villages. The total number of Taobao towns and villages ranks first in Hubei Province, becoming the first Taobao village cluster city in Hubei Province, forming a unique modern mode of "leading e-commerce enterprises + cooperatives + farmers + bases". By September 2019, there are more than 1,000 e-commerce enterprises in Zhijiang City, more than 8,000 e-commerce online stores and more than 20,000 people serving the e-commerce industry, which shows the rapid development of e-commerce in Zhijiang City. So why does Zhijiang City become an ecommerce gathering depression? What is the formation mechanism behind the Zhijiang mode? What is the operation mechanism of Zhijiang mode? What are the similarities and differences between Zhijiang mode and other typical modes? All these indicate that Zhijiang Taobao village has a typical case study value.

\subsection{Formation Mechanism of Zhijiang Mode}

\subsubsection{Convenient Transportation, Saving Logistics Cost}

Zhijiang City is the eastern gate of the Three Gorges of the Yangtze River, which is adjacent to the railway, airport, port and river. This unique location advantage provides convenience for fast and cheap logistics. In addition, Zhijiang City is located in the transitional zone from mountainous area in southwest Hubei to the Jianghan Plain. With convenient transportation and fast information exchange, a large number of young people have the opportunity to study in big cities, accumulating human resources for the development of Zhijiang e-commerce.

\subsubsection{Rich Resources and Competitive Products}

Zhijiang City is rich in surface water and underground water resources. The subtropical climate has improved the natural foundation for the diversified agricultural development of Zhijiang City. Zhijiang's water chestnut, pear, citrus, agate rice and houttuynia cordata have unique advantages, providing e-commerce with market competitive product resources. Different from the general Taobao village based on industrial products, Zhijiang City is a Taobao village based on agriculture products and independent development of industrial products, with unique local characteristics. 


\subsubsection{The Government Empowers and Provides Strong Backing}

Zhijiang City is a key development area and a first-class county in the whole province. The government has good financial strength to support the development of ecommerce. The e-commerce office in Zhijiang City is an independent government-directed institution. Instead of distorting and weakening market incentives, the government's support mode focuses on public services, market allocation of resources and professional knowledge of third-party services. Different levels of governments in Zhijiang City have adopted different incentive policies, such as store opening incentives, sales up to standard awards, free use of mass innovation space, e-commerce loan guarantee, etc.

\subsubsection{Enterprises Gathering to Improve E- commerce Marketing Power}

In Zhijiang City, there are national science and technology leading talent innovation driving center and the largest county-level mass Innovation Incubation Base, as well as e-commerce and electronic information industrial park, return home e-commerce service center, Maidada creation space and other innovation and entrepreneurship platforms. The gathering of many e-commerce industrial parks has attracted more than 10, 000 people to return home to start their own businesses. The "leading" power has driven the development of Taobao village and improved the digital skills of farmers. This has made e-commerce personnel more sensitive to numerous invisible and scattered consumer behaviors in the Internet world, which is to improve their e-commerce marketing power.

\subsubsection{Talents Return Home and Inject Innovation Vitality}

There are two kinds of leading figures in Taobao village of Zhijiang City. One is the grassroots who have gone out to start a business, they return home for various reasons and use the e-commerce knowledge they have learned in big cities to give feedback to Zhijiang City. The other is the grassroots who have a keen insight, they learn through the Internet to capture the wonderful e-commerce, groping to set foot on the e-commerce business. These two types of leaders, after success, but also to share their own experience to neighbors and friends, these e-commerce workers continue to learn from each other, so that the village's scale and marketing variety of Taobao gradually grow.

The triple edge attributes of marginal location, marginal groups and marginal products make the rise of Zhijiang Taobao village full of tension. The mode of "leading ecommerce enterprises + cooperatives + farmers + base" explored by Zhijiang City has promoted the prosperity of Zhijiang Taobao village, and the mutual learning and exchange of Zhijiang people makes Zhijiang Taobao Village continue to grow and develop. The rise and development of Zhijiang Taobao village is not determined by a single factor, but by many factors.

\subsection{Operation Mechanism of Zhijiang Mode}

How does Zhijiang mode actually work? What problems should be solved urgently in Zhijiang Taobao village? These issues are elaborated through an analysis of the typical enterprises in Zhijiang Taobao Village.

\subsubsection{Maimang Technology: Service-Oriented E-commerce Enterprises Lead the Development}

Zhijiang Maimang Information Technology Co. Ltd. was established in April 2018, which is a service-oriented ecommerce enterprise with four main sectors, namely smart marketing, brand operation, performance marketing and intelligent customers. At present, Maimang Technology selects Zhijiang characteristic fruits (such as oranges) to create replicable cases and build exclusive online sales solutions for Zhijiang agricultural and sideline products. The scheme is mainly divided into three categories: first, professional division of labor, saving labor costs; second, new retail, opening up channels and data; third, resource docking and exchanging seasonal products with other provinces. However, Maimang Technology also faces many upward difficulties, such as a scale lacking standards, a brand without promotion and talents without fresh power.

\subsubsection{Juyuan Company: "Cooperative + Member + Base + E-commerce"}

Established in October 2010, Juyuan Company is a modern agricultural economic entity integrating breeding seedlings, developing and planting new varieties, processing and marketing, and ecological tourism. At present, the cooperative has explored and established the industrial development mode of "cooperative + member + base + ecommerce", that is, every member of the cooperative should participate in production activities, farmers should plant in farm base during busy farming season, ecommerce personnel would carry out live pre-sales, order management and pre-sales and after-sales service, and farmers would go to the warehouse to process, package and send goods after picking. In addition, in 2019, Juyuan cooperative used modern intelligent system to paste source code for each orange, greatly solving the safety problem of agricultural products, and its brand strength was further promoted. 


\subsubsection{Maidada: Generation Operation from "Nothing"}

Maidada Company mainly distributes men's shoes. Yang Lin, the founder of the company, went to Zhejiang, Guangdong and Fujian to find suitable men's shoes manufacturers. It is packaged with the label of Maidada and then sold on the e-commerce platform, that is, the company operates with light assets. At the same time, the company closely follows the trend of digital technology and uses "desktop factory" to create a large number of daily necessities brands, subverting the traditional manufacturing modes and consumption patterns. Maidada's men's shoes distribution mode mainly relies on the services of local mature e-commerce enterprises and the development of e-commerce platform, which is the industrial products downward road opened after the success of agricultural products upward in Zhijiang Taobao Village. Now, the transformation problems faced by the company are how to use big data network to track the trend of consumer demand, reduce warehouse management costs, and further improve the added value of products.

The differences between Zhijiang mode and coastal Taobao village development mode can be reflected in the following aspects: 1) the Zhijiang Taobao village attracts talents to return home and start their own businesses, focusing on service provision, giving full play to the decisive role of the market in the allocation of resources, while service providers are empowered to provide a leading role. While the coastal Taobao village is mainly driven by the rural talents and then the government follows up to promote the development; 2) Zhijiang City created a public brand of "Zhizi Youwei", which gathered all kinds of disordered agricultural product brands to form joint development and improve competitiveness; 3) the coastal Taobao village is either product-oriented or marketoriented, while Zhijiang Taobao village is a diversified and mixed development, making use of its own product advantages and market-oriented to create substitute operation products, namely agricultural products At the same time, it promotes the decline of industrial products.

By discussing the formation mechanism, operation mechanism and related comparisons of the Zhijiang mode, we can summarize three main characteristics of Zhijiang mode: 1) the "three edges", namely, the marginal areas, marginal groups and marginal product combination to create Taobao village; 2) the government-enterprise collaborative development, government empowerment "addition"; 3) the market-oriented free industrial division of labor organization mode, online and offline, local and foreign supply chain network seamless docking. Of course, at present, the development of Zhijiang Taobao village is still facing many problems, for example, it is still marginalized development, the radiation-driven ability is relatively weak, the product packaging and transportation is still difficult, there is no introduction of external talents, it is difficult to find a new combination of products and so on. Therefore, Zhijiang Taobao village needs to constantly communicate with the eastern Taobao village, only in this way can Zhijiang City gradually build a healthy ecological sustainable digital village.

The central and western regions can learn from the successful experience of Zhijiang City. When building Taobao village, they should first consider the question of what to sell, whether to sell local products or to operate on behalf of others. Secondly, they should innovate in the selection of products, don't pile up to avoid vicious competition, to create a public brand like "brandish flavor". Finally, they need to plan the industrial chain seriously, and build a perfect industrial chain of "Internet plus talent + industrial incubation" from the aspects of e-commerce education, industry investment, industrial operation, industry cultivation.

\section{CONCLUSION}

The success of Zhijiang Taobao village fully proves the feasibility of e-commerce development in rural areas. The development of rural e-commerce has played a role in promoting the construction of beautiful digital countryside. Zhijiang's "leading e-commerce enterprises + cooperatives + farmers + base" mode is replicable, and can become a mode for the development of central and western regions. The problems exposed in the process of Zhijiang's development are also worth pondering.

Nowadays, Taobao Village is in the urbanization characterization of industry promotion, facilities support, and rapid expansion of space. At this stage, the government empowerment to solve the problems of office space rent, related personnel e-commerce knowledge training and provide entrepreneurship incentives. Currently there are many villages and town units that want to develop Taobao villages, but they cannot find a clear product positioning. On one hand, there are no distinctive agricultural products, and on the other hand, there is no competitive manufacturing industry. At this time, they need to balance the gathering points and find the products suitable for their own regional positioning in many difficult choices. Taobao Village is a self-developed and cluster development type, which has now formed an industrial chain, the next step will gradually appear a new industrialized system, and the development of the new industrialization system can not be separated from the Internet, cloud computing and other data support.

\section{ENLIGHTENMENTS}

Through the analysis of Zhijiang mode and relevant successful cases, the following opinions and suggestions can be put forward for the transformation and development of Taobao village in China.

Gradually allow service providers to lead development instead of government-led development. The government can only support a limited amount of content. More service providers need to lead the development, cultivation or introduce service providers locally to solve the problem of 
specialized services from primary products to commodities That is, under the guidance of service providers, Taobao village will be transformed gradually. Driven by the service providers, multi-party governance and collaborative governance of various subjects will be carried out to create a beautiful village.

Balance gathering points to improve e-commerce marketing power. To improve the marketing power of ecommerce is to conduct a deep understanding of the invisible consumers on the opposite side of the Internet. To make the mass production as niche as possible after providing the service, and to go out of the way to suit their own distinctive characteristics, such as refining the consumer's demand, innovate small and beautiful products, superimposed on the form of service, and improve the operational capabilities. At the same time, all kinds of offline and online modes should be constantly integrated and innovated to reconstruct the consumer market pattern, focusing on consumer immersive shopping experience, logistics distribution efficiency and convenience of purchase.

Using data to serve the industry. Using the data, we can sort out and integrate the mode of Taobao village which has been successfully developed at present, create a data mode section, construct a downward system of consumer goods and an upward system of agricultural products, which will facilitate the subsequent reference and development of other regions in the future. In addition, data services agriculture, digital production, digital logistics, digital sales and digital finance, use the new infrastructure of digital agriculture to realize the transformation to a digital agricultural country, effectively link farmers and consumers, better protection of the personalized needs of consumers and ensure food safety.

\section{ACKNOWLEDGMENT}

Fund Project: Ministry of education Youth Fund for Humanities and Social Sciences Research (17YJC790144)

The author would like to thank Zhijiang municipal government for providing the opportunity of exchange, study and research on "the Third Forum on transformation and development of Taobao village in China".

\section{REFERENCES}

[1] Ali Research Institute, China Institute of rural development, Zhejiang University. Report on e- commerce of agricultural products in 2020 [R/OL]. 2020 .

[2] Zhendong Luo, Fangfang Chen and Jianshu Shan Towards Taobao village 3.0: a feasible way for Rural Revitalization [J]. Small Town Construction, 2019, 37(02): pp. 43-49.

[3] JunchengZhang and Linbang Fan. Research summary of rural e-commerce Taobao village mode [J]. Logistics Forum, 2019,41 (11):pp. 30-35.

[4] Yajun Liu and Xinmin Chu. Research on the industrial evolution of "Taobao village" in China[J] Technology and Industry, 2017, 02(08): pp. 29-36.

[5] Lili Cui, Lijing Wang and Jingquan Wang. Empirical analysis of social innovation factors promoting e-commerce development of "Taobao village" - a case study of Lishui, Zhejiang Province [J]. China Rural Economy, 2014, 12: pp. 50-52.

[6] Yanhong Cui. Practical experience and Enlightenment of Taobao village in Cao county [J]. China Business Theory, 2019,24 (18): pp. 18-19.

[7] Bangyao Zhu et al. Spatial aggregation pattern and influencing factors of China's "Taobao village" under $\mathrm{C} 2 \mathrm{C}$ e-commerce mode [J]. Economic Geography, 2016,36 (04): pp. 92-98.

[8] Yiwu Zeng, Hongdong Guo. Formation mechanism of agricultural products Taobao Village: a multi-case study [J]. Agricultural Economic Issues, 2016, 37 (04) pp. $39-48+111$.

[9] Ali Research Institute, spatial planning research center of Nanjing University, etc. ten years of Taobao Village: Digital Economy Promoting Rural Revitalization [R/OL]. 2019.

[10] Haiyun Yu, Changyu Wang and Zengyao Zhao. Research on the motivation and mechanism of rural ecommerce entrepreneurship Agglomeration - a case study of "Taobao village" in Shuyang, Jiangsu Province [J]. Economic Management, 2018,40 (12):pp. 39-54. 